\title{
Hydration and Strength Development of Cementitious Materials Prepared with Phosphorous-Bearing Clinkers
}

\author{
Lilan Xie ${ }^{1,2, *}$, Min Deng ${ }^{1, *}$, Jinhui Tang ${ }^{3}$ and Kaiwei Liu ${ }^{4}$ \\ 1 College of Materials Science and Engineering, Nanjing Tech University, Nanjing 211816, China \\ 2 College of Materials and Construction Engineering, Guizhou Normal College, Guiyang 550018, China \\ 3 School of Materials Science and Engineering, Southeast University, Nanjing 211189, China; t_jinhui@163.com \\ 4 Anhui Province Engineering Laboratory of Advanced Building Materials, Anhui Jianzhu University, \\ Hefei 230601, China; liukaiwei1985@gmail.com \\ * Correspondence: xiell_1979@163.com (L.X.); dengmin@njtech.edu.cn (M.D.)
}

check for

updates

Citation: Xie, L.; Deng, M.; Tang, J.; Liu, K. Hydration and Strength Development of Cementitious Materials Prepared with Phosphorous-Bearing Clinkers. Materials 2021, 14, 508. https:// doi.org/10.3390/ma14030508

Received: 17 December 2020

Accepted: 19 January 2021

Published: 21 January 2021

Publisher's Note: MDPI stays neutral with regard to jurisdictional claims in published maps and institutional affiliations.

Copyright: (c) 2021 by the authors. Licensee MDPI, Basel, Switzerland. This article is an open access article distributed under the terms and conditions of the Creative Commons Attribution (CC BY) license (https:// creativecommons.org/licenses/by/ $4.0 /)$.

\begin{abstract}
To rationally use low-grade phosphorous limestone as the raw materials for cement production, the influence of phosphorous introduced by fluorapatite during the clinker calcination process on the mechanical properties of cementitious materials is investigated. Hydration kinetics, phase evolutions, and microstructure of cement pastes have been studied by using calorimetry, $X$-ray diffraction (XRD), and scanning electron microscopy (SEM). The results indicate that the mechanical properties of cementitious materials can be slightly improved due to the mineralization effect of the small amount of phosphorous in the clinker and significantly decreased with an increase of phosphorous. High content of phosphorous will reduce the content of $\mathrm{C}_{3} \mathrm{~S}$ and make the formation of $\alpha^{\prime}-\mathrm{C}_{2} \mathrm{~S}-\mathrm{xC} \mathrm{C}_{3} \mathrm{P}(\mathrm{x}$ : $0-0.05)$, whose hydration reactivity is rather lower, such that on the one hand less-hydrated products, such as calcium silicate hydrate (C-S-H) gel, can be obtained, and on the other hand, the hydration reaction will be slowed by severely prolonging the induction period. Interestingly, small particles can be observed on the surface of hydration products, but no new phase can be detected by XRD. When the content of $\mathrm{P}_{2} \mathrm{O}_{5}$ is $2.0 \%$, the cement can meet the requirements of P.II 42.5 cement in China. Hopefully, this can provide significant guidance for the use of cement prepared by fluorapatite as raw material.
\end{abstract}

Keywords: phosphorous-containing cement; $\alpha^{\prime}-\mathrm{C}_{2} \mathrm{~S}-\mathrm{xC} \mathrm{C}_{3} \mathrm{P}$; mechanical property; hydration mechanism

\section{Introduction}

Phosphorus has a significant effect on the hydration performance of cement, such as the hydration rate of cement clinker, and the strength of cement-based materials [1-5]. Phosphorus in cement usually comes from two sources; one is phosphorus introduced in the raw materials for cement production or alternative fuels [6-8], and the other is the partial replacement of cement by solid waste containing phosphorus (phosphorus slag, phosphor-gypsum, phosphorus tailings, etc.) [9-11].

The phosphorus contained in cement clinker is usually called internal phosphorus, while other phosphorus introduced in cement is called external phosphorus. Many studies have been conducted on the influence of externally introduced phosphorus on cement hydration performance [12-16]. Lieber [1] used dipolyphosphate, tripolyphosphate, tetrapolyphosphate, and polyphosphate to study the effects of different soluble phosphates on cement hydration. According to the properties and content of the decomposed phosphate in the mixed solution, it is considered that phosphate ions adsorb particles on the surface of the clinker and the formation of calcium phosphate complexes probably prevents the normal process of hydration. Chen et al. [3] mixed chemical reagent $\mathrm{P}_{2} \mathrm{O}_{5}$ with Portland cement to study the influence of $\mathrm{P}_{2} \mathrm{O}_{5}$ on the hydration mechanism of Portland cement. The results show that when the $\mathrm{P}_{2} \mathrm{O}_{5}$ content is up to $3.5 \%$, the total heat of hydration of Portland cement is reduced by $32.6 \%$, and the initial and final settings of Portland cement 
are delayed by $1.10 \mathrm{~h}$ and $12.54 \mathrm{~h}$, respectively. The reason for this is that new hydration products form during the hydration of $\mathrm{C}_{3} \mathrm{~A}$, which increases hydration resistance and apparent activation energy of cement during the acceleration period, and delays the hydration process of $\mathrm{C}_{3} \mathrm{~S}$ and $\beta-\mathrm{C}_{2} \mathrm{~S}$.

The mechanism of retardation of poorly soluble phosphate and soluble phosphate on cement is different. Cheng et al. [17] believe that the insoluble phosphate is gradually converted into hydroxyapatite in alkaline solution and adsorbed on the surface of the hydration product, resulting in an increase in the compactness of the hydration product film. Boughanmi [10] conducted research on phosphorus-containing industrial clinker in Tunisia, and the results showed that when the content of $\mathrm{P}_{2} \mathrm{O}_{5}$ in the clinker is $0.5-1.1 \%$, it has no significant effect on the hydration activity and strength development of cement. "International Cement Process Information Collection" [18] mentioned that the allowable content of $\mathrm{P}_{2} \mathrm{O}_{5}$ in the clinker is about $2.5 \%$ if raw materials containing phosphorus. Sometimes, the content of $\mathrm{P}_{2} \mathrm{O}_{5}$ is very low, even as low as $0.5 \%$, but it still causes a significant decrease in cement strength, especially the early strength of cement.

Therefore, it is interesting to investigate the hydration and strength development of cementitious materials prepared with phosphorous-bearing clinker. In fact, lots of work regarding the influence of external addition of phosphors by chemical agent on the property of cement has been done in the lab, which is not closely related with real-world situations. At present, the hydration and mechanical properties of Portland cement clinker prepared with limestone containing fluorapatite as raw material are rarely reported. In this paper, phosphorus-containing limestone, from a cement plant in Angola, was used to prepare cement clinker, and furthermore to study the effect of phosphorus on the hydration activity of cement clinker, and the influence of phosphorous in cement clinker on the phase evolution and morphology. Moreover, the degree of hydration of the cement was studied through calorimetry, TG-DSC, and mechanical performance testing. The results can be used as the guidance for cement production using low-grade phosphorous-bearing limestone.

\section{Experimental}

\subsection{Materials}

\subsubsection{Cements}

Clinkers with different phosphorus contents were experimentally prepared with raw reals obtained by mixing phosphorus-containing limestone, normal limestone, clay, iron ore powder, and fly ash. The phosphorus-containing limestone was derived from Angola (Cimangola, Luanda, Angola). KH (lime saturation factor, SM (silica modulus), and IM (iron modulus) for clinkers were $0.96,2.10$, and 1.50. The temperature for calcining clinkers was $1450{ }^{\circ} \mathrm{C}$. The content of P2O5 in the clinkers was $0.0 \%, 0.5 \%, 1.0 \%, 1.5 \%, 2.0 \%$, and $2.5 \%$ by adjusting the mass ratio of phosphorus-containing limestone and limestone. The chemical compositions of clinkers obtained by XRF (X-ray Fluorescence) are shown in Table 1 . The content of $C_{3} S$ and $C_{2} S$ (including $\beta-C_{2} S$ and $\alpha^{\prime}-C_{2} S-x C_{3} P$ ) was measured by Retiveld refinements of powder XRD. Mixtures of $95 \%$ clinkers and $5 \%$ natural gypsum were ground in a lab mill to obtain cements. The particles of the obtained cements all passed through $80 \mu \mathrm{m}$ sieve.

Table 1. Influence of $\mathrm{P}_{2} \mathrm{O}_{5}$ on the content of $\mathrm{C}_{3} \mathrm{~S}$ and $\mathrm{C}_{2} \mathrm{~S}$ in clinkers /wt.\%.

\begin{tabular}{ccccccc}
\hline $\mathbf{P}_{\mathbf{2}} \mathbf{O}_{\mathbf{5}}$ & $\mathbf{0}$ & $\mathbf{0 . 5}$ & $\mathbf{1 . 0}$ & $\mathbf{1 . 5}$ & $\mathbf{2 . 0}$ & $\mathbf{2 . 5}$ \\
\hline $\mathrm{C}_{3} \mathrm{~S}$ & 53.06 & 53.64 & 47.22 & 45.37 & 44.83 & 42.69 \\
$\mathrm{C}_{2} \mathrm{~S}$ & 23.52 & 21.04 & 31.55 & 32.54 & 31.40 & 30.78 \\
\hline
\end{tabular}

\subsubsection{Sand}

Standard sand from Pingtan, Fujian province, China was used. The purity of the sand used in this paper was higher than $98 \%$. The particle size varied from $0.08 \mathrm{~mm}-2.00 \mathrm{~mm}$, which is shown in Figure 1. 


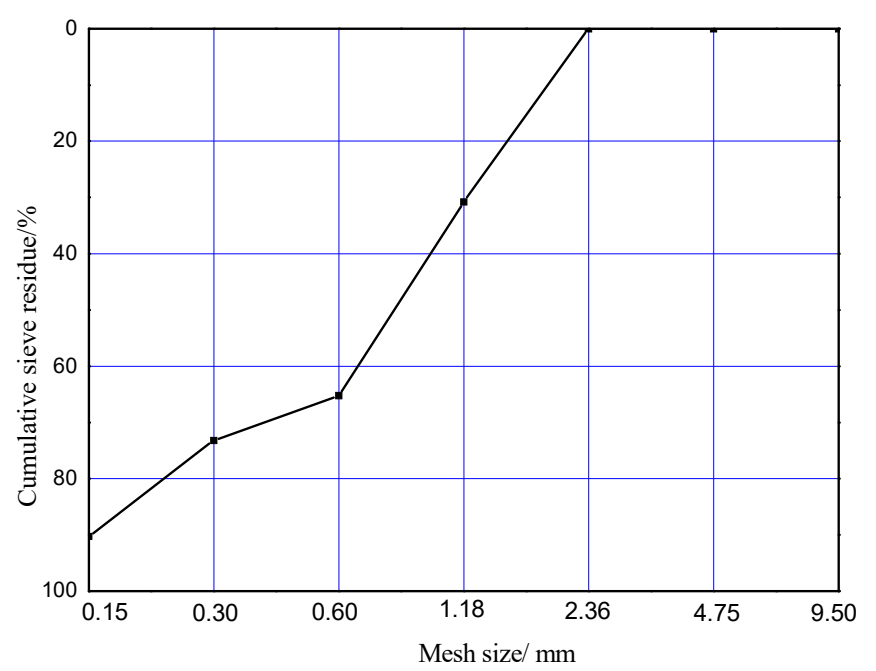

Figure 1. The gradation diagram of sand.

\subsection{Test Methods}

\subsubsection{Hydration Heat}

The TAM AIR Thermstate 90 thermal activity microcalorimeter of American TA Company (New Castle, DE, USA) was used for calorimetric analysis. The water-binder ratio of the test sample was 0.5 and the mass of cement was about $1.00 \mathrm{~g}$. The temperature was kept at $20^{\circ} \mathrm{C}$.

\subsubsection{Phase Compositions of Cement Pastes}

The cement pastes at certain curing ages were crushed and soaked in ethyl alcohol for 2 days to stop hydration. They were then ground to pass through an $80 \mu \mathrm{m}$ sieve and vacuum-dried at $70{ }^{\circ} \mathrm{C}$. The hydration products of cement pastes were determined by SmartLab rotary target $\mathrm{X}$-ray diffractometer (Rigaku, Tokyo, Japan) equipped with copper, as were the target materials from Rigaku Company, Japan. The scanning rate was $10^{\circ} / \mathrm{min}$. Working voltage and current were $40 \mathrm{kV}$ and $30 \mathrm{~mA}$. A STA449F3 thermal analyzer (NETCSZH, Selb, Germany) was used to analyze the phases of cement pastes with $\mathrm{N}_{2}$ protective atmosphere. The reference substance was $\alpha-\mathrm{Al}_{2} \mathrm{O}_{3}$. The samples were heated from room temperature to $900{ }^{\circ} \mathrm{C}$ at a rate of $10{ }^{\circ} \mathrm{C} / \mathrm{min}$.

\subsubsection{Microstructures}

A S-4800 scanning electron microscope produced by HITACHI (Tokyo, Japan) was used to analyze the microstructure of cement pastes at different ages.

\subsubsection{Strength of Cement Pastes and Mortars}

Cement pastes of $20 \mathrm{~mm} \times 20 \mathrm{~mm} \times 20 \mathrm{~mm}$ were cast with $0.28 \mathrm{~W} / \mathrm{C}$. They were then cured in a moist container at $20^{\circ} \mathrm{C} \pm 2{ }^{\circ} \mathrm{C}$ for $24 \mathrm{~h}$. They were de-molded and immersed in $20^{\circ} \mathrm{C}$ water. Compressive strengths of the cement pastes cured in water for 2 and 27 days were tested.

Mortars of $40 \mathrm{~mm} \times 40 \mathrm{~mm} \times 160 \mathrm{~mm}$ were cast with cements, sand, and water. The ratio of cement to sand was $1: 3$. W/C was 0.50 . The mortars were then cured in a moist container at $20^{\circ} \mathrm{C} \pm 2{ }^{\circ} \mathrm{C}$ for $24 \mathrm{~h}$. They were de-molded and immersed in $20^{\circ} \mathrm{C}$ water. The compressive and flexural strengths of mortars cure for 3 and 28 days were tested according to GB/T 17671-1999 “Test method for strength of mortars". A detailed proportion of both cement pastes and mortars is listed in Table 2. 
Table 2. The proportion of cement paste and mortars.

\begin{tabular}{cccc}
\hline & Cement/g & Sand/g & Water/g \\
\hline Cement pastes & 450 & 0 & 126 \\
Mortars & 450 & 1350 & 225 \\
\hline
\end{tabular}

\section{Results and Discussion}

\subsection{Heat of Hydration}

To study the effect of $\mathrm{P}_{2} \mathrm{O}_{5}$ content on the hydration process of cement, calorimetric analysis was carried out on the prepared cement samples, as shown in Figure 2. The characteristic values of the hydration heat curve of phosphorous-containing cement are listed in Table 3.

From Figure 2, compared with plain sample, the induction period for those phosphorouscontaining cement will be prolonged. In addition, the higher the $\mathrm{P}_{2} \mathrm{O}_{5}$, the longer the induction period. Moreover, the maximum hydration heat flow decreased with the increase of the content of $\mathrm{P}_{2} \mathrm{O}_{5}$.

According to characteristic points in the hydration heat curve of cement, the hydration heat curve is divided into the following stages [19]: the end of the induction period, which means the beginning of the acceleration period, and the end of the acceleration period, when the heat release rate reaches maximum value. Based on the test results of hydration heat in Figure 2, the characteristic parameters of hydration heat curves of cement with different $\mathrm{P}_{2} \mathrm{O}_{5}$ contents are listed in Table 3.

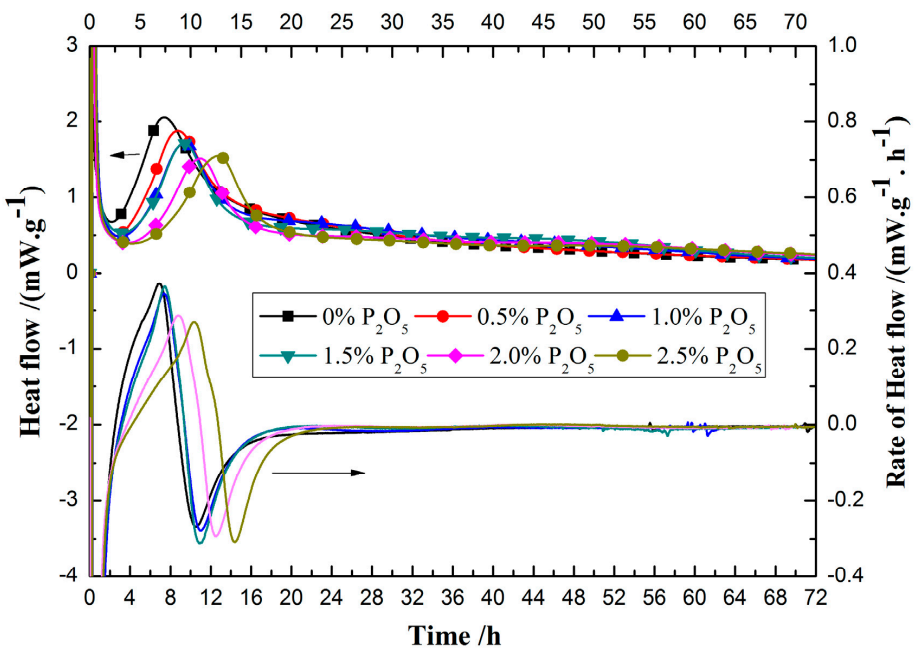

Figure 2. Influences phosphorus on the hydration heat of cement.

The induction period was prolonged separately by $0.51 \mathrm{~h}, 0.86 \mathrm{~h}, 1.15 \mathrm{~h}, 1.55 \mathrm{~h}$, and $3.28 \mathrm{~h}$ when the content of $\mathrm{P}_{2} \mathrm{O}_{5}$ in the clinker increased from $0.5 \%$ to $2.5 \%$. With an increase of $\mathrm{P}_{2} \mathrm{O}_{5}$ content in the clinker, the minimal hydration heat flow decreases gradually. When the $\mathrm{P}_{2} \mathrm{O}_{5}$ content in the clinker is up to $2.5 \%$, the hydration heat flow decreases to $0.40 \mathrm{~mW} \cdot \mathrm{g}^{-1}$ in induction, which means the existence of phosphorous will slow down the reaction rate of cement clinker. At the same time, the maximum hydration heat flow also decreases with the increase of $\mathrm{P}_{2} \mathrm{O}_{5}$ content in the clinker. Total hydration heat will first increase with the increase of the $\mathrm{P}_{2} \mathrm{O}_{5}$ content. However, total hydration heat will decrease if the content of $\mathrm{P}_{2} \mathrm{O}_{5}$ is higher than $2.0 \%$, which may be closely related to the total content of silicate phase in cement. 
Table 3. Eigenvalues of hydration heat flow released by phosphorus-bearing cements.

\begin{tabular}{cccccc}
\hline $\begin{array}{c}\mathbf{P}_{\mathbf{2}} \mathbf{O}_{\mathbf{5}} \text { in } \\
\text { Clinker/\% }\end{array}$ & $\begin{array}{c}\text { Total Hydration } \\
\text { Heat at 3 days/J·g }\end{array}$ & $\begin{array}{c}\text { Time at End of } \\
\text { Induction/h }\end{array}$ & $\begin{array}{c}\text { Minimal Hydration } \\
\text { Heat Flow/mW/g }\end{array}$ & $\begin{array}{c}\text { Time at End of } \\
\text { Acceleration } \\
\text { Period/h }\end{array}$ & $\begin{array}{c}\text { Maximum } \\
\text { Hydration Heat } \\
\text { Flow } / \mathbf{m W} \cdot \mathbf{g}^{-\mathbf{1}}\end{array}$ \\
\hline 0.0 & 151.7 & 2.17 & 0.67 & 7.38 & 2.06 \\
0.5 & 157.3 & 2.68 & 0.49 & 8.75 & 1.88 \\
1.0 & 158.0 & 3.03 & 0.48 & 9.38 & 1.71 \\
1.5 & 158.3 & 3.32 & 0.45 & 9.38 & 1.72 \\
2.0 & 141.9 & 3.72 & 0.42 & 10.96 & 1.52 \\
2.5 & 142.7 & 5.45 & 0.40 & 12.73 & 1.55 \\
\hline
\end{tabular}

\subsection{Hydration Products in Cement Pastes}

The cement pastes were prepared with water to cement $(\mathrm{W} / \mathrm{C})$ ratio of 0.28 . The pastes were analyzed by XRD after hydration for $0.5,1,3$, and 28 days. The results are shown in Figures 3-6. Moreover, the typical hydration products (ettringite, calcium hydroxide $(\mathrm{CH})$ ) and unhydrated clinker minerals, a new phase of $\alpha^{\prime}-\mathrm{C}_{2} \mathrm{~S}-\mathrm{x} \mathrm{C}_{3} \mathrm{P}$, were detected in the samples containing phosphorous. After hydration of $12 \mathrm{~h}$, the intensity of $\mathrm{CH}$ and ettringite (AFt) decreased with the increase of the content of $\mathrm{P}_{2} \mathrm{O}_{5}$. Additionally, the intensity for $\mathrm{C}_{3} \mathrm{~S}$ was also gradually weakened with the increase of content of $\mathrm{P}_{2} \mathrm{O}_{5}$.

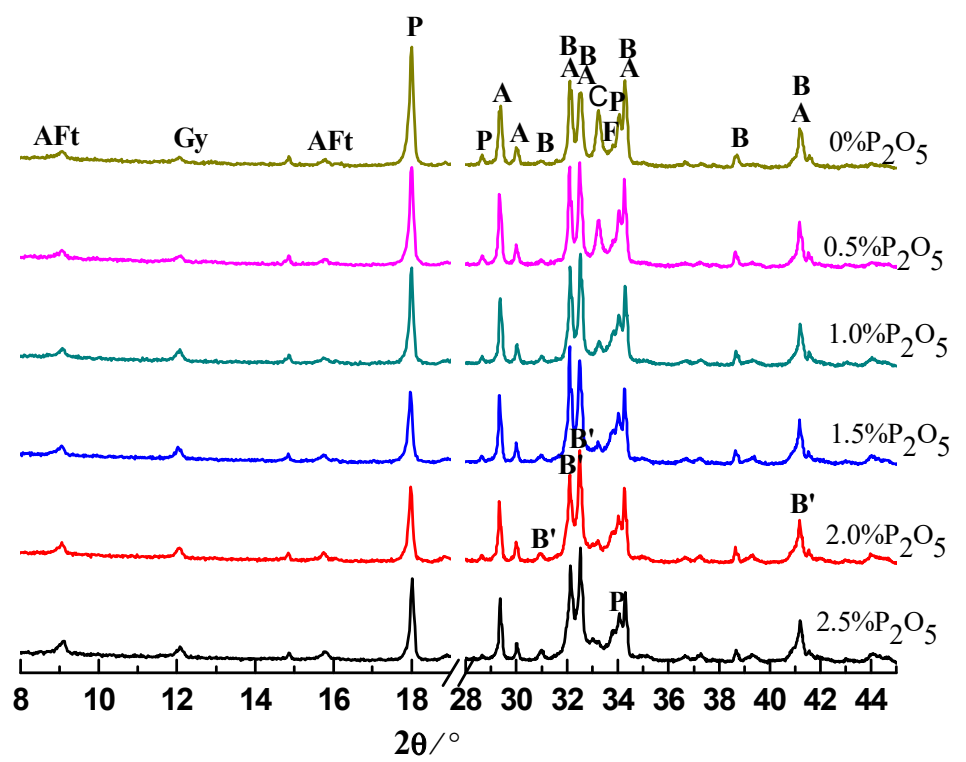

Figure 3. XRD patterns of cement pastes hydrated for 0.5 day. $A: C_{3} S ; B: \beta-C_{2} S ; F: C_{4} A F ; C: C_{3} A ; P$ : $\mathrm{CH} ; \mathrm{B}^{\prime}: \alpha^{\prime}-\mathrm{C}_{2} \mathrm{~S}-\mathrm{xC}_{3} \mathrm{P}$.

With the further hydration of cement for $24 \mathrm{~h}$, unhydrated clinker minerals were continuously decreased, corresponding to the enhancement of the intensity of hydration products compared to those samples hydrating for $12 \mathrm{~h}$. However, it is worth noticing that for those samples containing phosphorous, especially for the sample containing $2.5 \% \mathrm{P}_{2} \mathrm{O}_{5}$, the intensity of the peak for the $\alpha^{\prime}-\mathrm{C}_{2} \mathrm{~S}-\mathrm{xC}_{3} \mathrm{P}$ was still stronger, which means low reactivity of the cement containing phosphorous. 


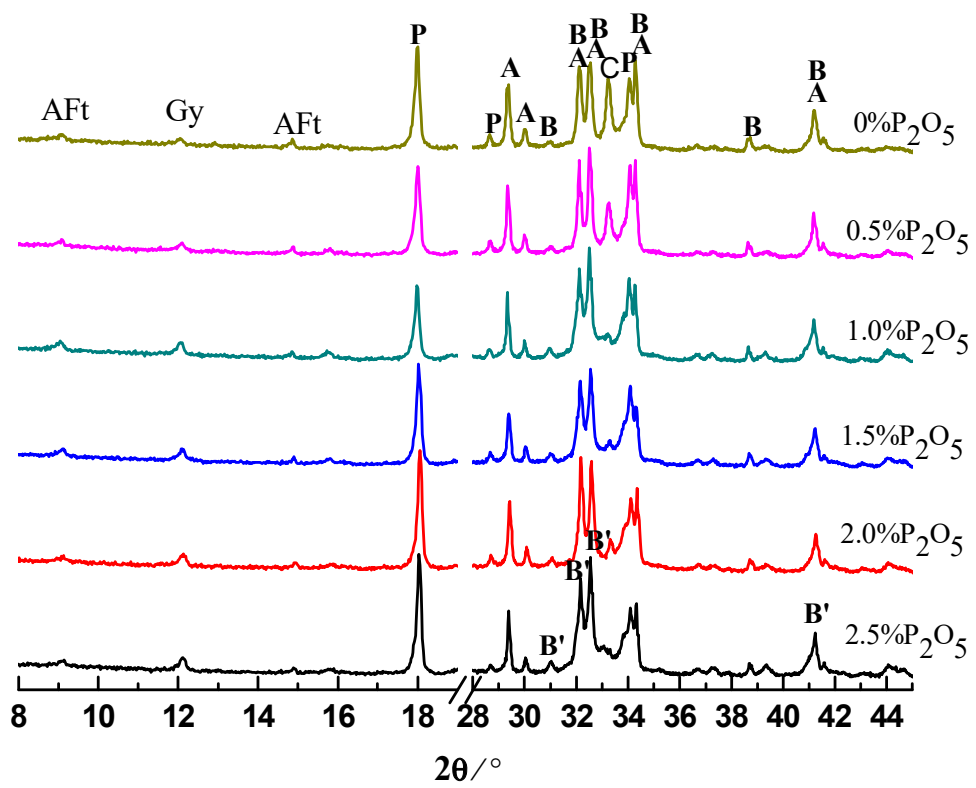

Figure 4. XRD patterns of cement pastes hydrated for 1 day. A: $C_{3} S ; B: \beta-C_{2} S ; F: C_{4} A F ; C: C_{3} A ; P$ : $\mathrm{CH} ; \mathrm{B}^{\prime}: \alpha^{\prime}-\mathrm{C}_{2} \mathrm{~S}-\mathrm{xC} \mathrm{C}_{3} \mathrm{P}$.

Regarding the XRD results for those samples at 3 days, compared to the controlling samples, the intensity for $\mathrm{CH}$ significantly decreased due to the existence of phosphorous. This is mainly because phosphorous can inhibit the hydration of cement, which has been supported by the extension of the induction period. Unlike normal conditions, for those samples containing phosphorous, we propose that the new phases of $\alpha^{\prime}-C_{2} S-x C_{3} P$ be characterized with low reactivity where intensity of the peak can still be obviously observed.

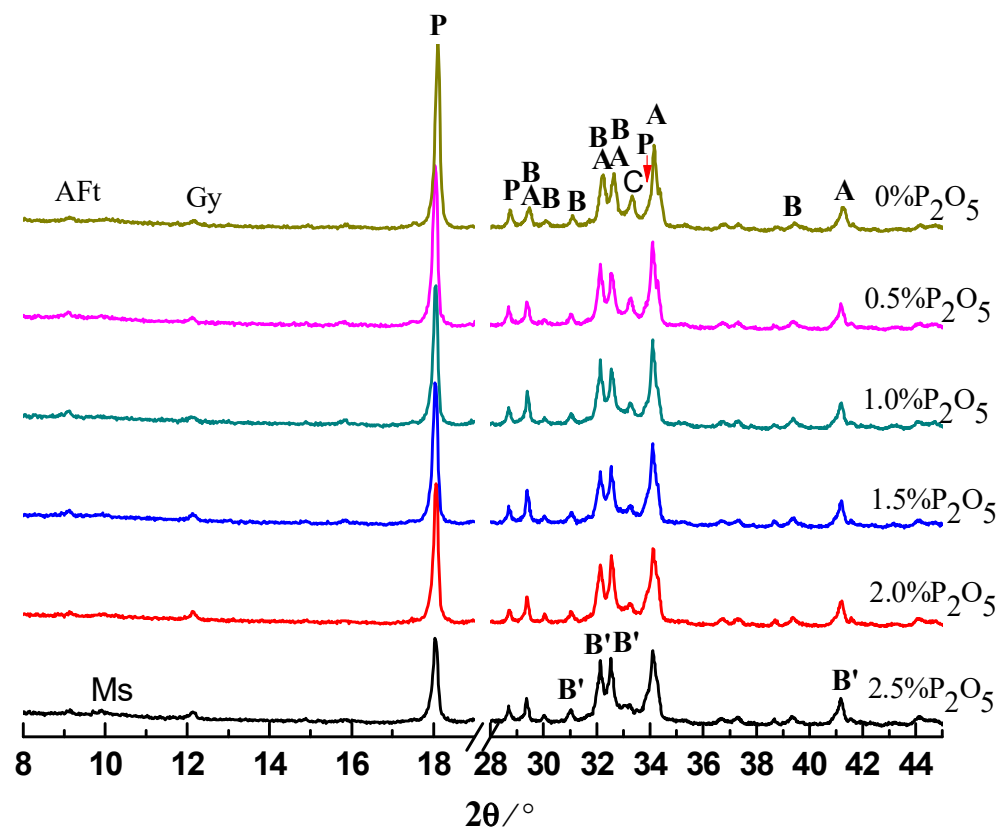

Figure 5. XRD patterns of cement pastes hydrated for 3 days. $A: C_{3} S ; B$ : $\beta-C_{2} S ; P: C H ; M s: A F m ; B^{\prime}$ : $\alpha^{\prime}-\mathrm{C}_{2} \mathrm{~S}-0.05 \mathrm{C}_{3} \mathrm{P}$.

The products of cement pastes after hydration for 28 days are listed in Figure 6, mainly including $\mathrm{CH}$, Aft, and AFm. It indicates that for the controlling sample, because of the consumption of $\mathrm{C}_{3} \mathrm{~S}$ and $\mathrm{C}_{2} \mathrm{~S}$, the corresponding intensity has become far weaker compared to those samples at early stage. However, it is worth noting that the intensity for 
$\alpha^{\prime}-\mathrm{C}_{2} \mathrm{~S}-\mathrm{xC} \mathrm{C}_{3} \mathrm{P}$ in those cement pastes containing high phosphorous was still stronger, to some extent suggesting low hydration activity for $\alpha^{\prime}-C_{2} S-x C_{3} P$, which is different from Li's results that suggested $\mathrm{P}$ doping $\alpha_{\mathrm{H}}-\mathrm{C}_{2}$ S exerted a high hydraulic reactivity [20]. We speculate that this is mainly because of the distinguished addition of phosphorous weather by chemical agent or phosphorous-bearing materials, causing different effects on the structure of $C_{2} S$, which needs to be further investigated. Moreover, it is interesting that regardless of the length of the curing time, the characteristic peak of calcium phosphate was not detected, which agrees with the previous reports [3,17].

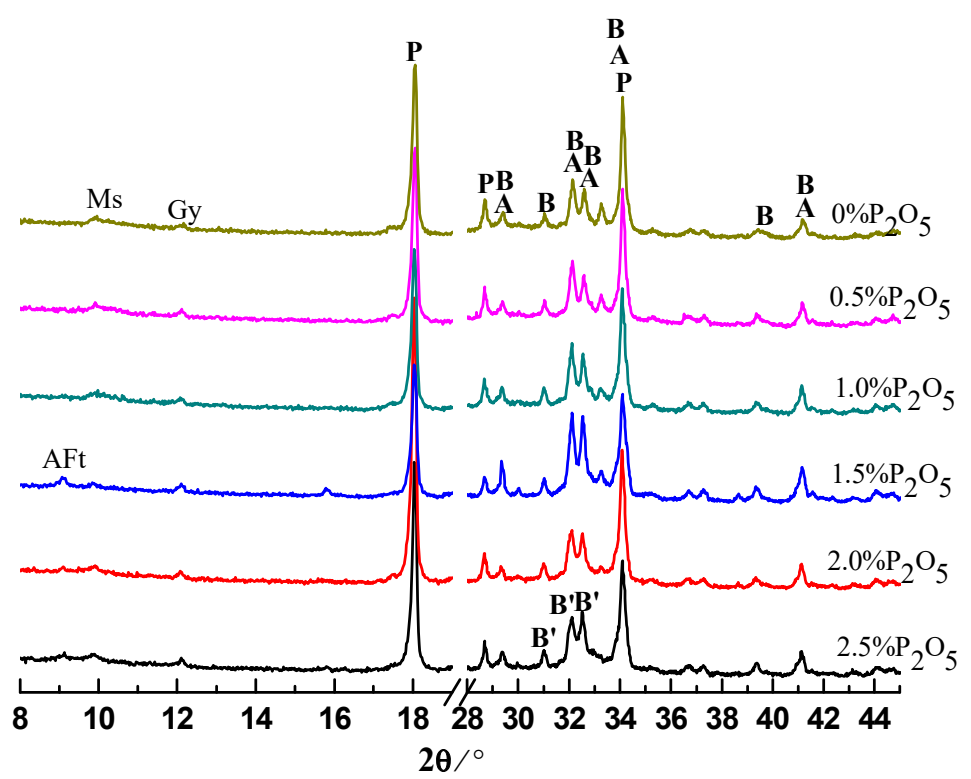

Figure 6. XRD patterns of cement pastes hydrated for 28 days. $A: C_{3} S ; B: \beta-C_{2} S ; P: C H ; M s: A F m ; B^{\prime}$ : $\alpha^{\prime}-C_{2} S-0.05 C_{3} P$.

\subsection{Effect of Phosphorous on the DSC-TG of Cement Pastes}

Figure 7 shows the DSC results of cement pastes hydrated for 3 and 28 days. The endothermic peaks at $100-105^{\circ} \mathrm{C}$ and $165-175^{\circ} \mathrm{C}$ were caused by dehydration of C-S-H gel and AFt or AFm. The endothermic peaks at $445-455^{\circ} \mathrm{C}$ and $670-700{ }^{\circ} \mathrm{C}$ were believed to be brought about by decomposition of $\mathrm{CH}$ and $\mathrm{CaCO}_{3}$ that was formed by the carbonation of $\mathrm{CH}$ [21-23], respectively. The results showed that there seems to be no difference in hydration products for cement pastes with and without phosphorus-bearing phases in clinkers.

Based on the results of TG-DSC, the contents of $\mathrm{CH}$ in those samples were calculated by Equation (1). However, accounting for the effective amount of $C_{3} S$ and $C_{2} S$ whose main hydration products were $\mathrm{CH}$, the normalized value of $\mathrm{CH}$ by $\mathrm{C}_{3} \mathrm{~S}$ and $\mathrm{C}_{2} \mathrm{~S}$ is presented in Figure 8. As mentioned before [24-26], because of the mineralization caused by the low dosage of fluorapatite $\left(0.5 \% \mathrm{P}_{2} \mathrm{O}_{5}\right)$, compared to the controlling sample, a slight increase can be detected after curing for 3 days. However, when the content of $\mathrm{P}_{2} \mathrm{O}_{5}$ increases to $1.0 \%$, a sudden decrease for $\mathrm{CH}$ happens, by $6.5 \%$ compared to the plain sample. In addition, when the content of $\mathrm{P}_{2} \mathrm{O}_{5}$ was higher than $1.0 \%$, the $\mathrm{CH}$ fluctuated around $18 \%$. Then, after curing for 28 days, except for the $0.5 \% \mathrm{P}_{2} \mathrm{O}_{5}$ whose mineralization effect makes $\mathrm{CH}$ suffer a slight increase, the continuous increase in the amount of $\mathrm{P}_{2} \mathrm{O}_{5}$ causes a corresponding drop in $\mathrm{CH}$. The results showed that when the content of $\mathrm{P}_{2} \mathrm{O}_{5}$ was $2.5 \%$, the amount of $\mathrm{CH}$ at 28 days decreased by $12.1 \%$ in contrast to the controlling sample, which matched the development of the compressive strength of cement pastes well, both at 3 and at 28 days.

$$
m_{\mathrm{Ca}(\mathrm{OH})_{2}}=\left(\frac{\Delta m_{1}}{18}+\frac{\Delta m_{2}}{44} \times \frac{2}{3}\right) \times 74
$$


$m_{\mathrm{Ca}(\mathrm{OH})_{2}}$ : Mass of $\mathrm{Ca}(\mathrm{OH})_{2}$;

$\Delta m_{1}$ : Mass change of $\mathrm{Ca}(\mathrm{OH})_{2} ;$

$\Delta m_{2}$ : Mass change of $\mathrm{CaCO}_{3}$.
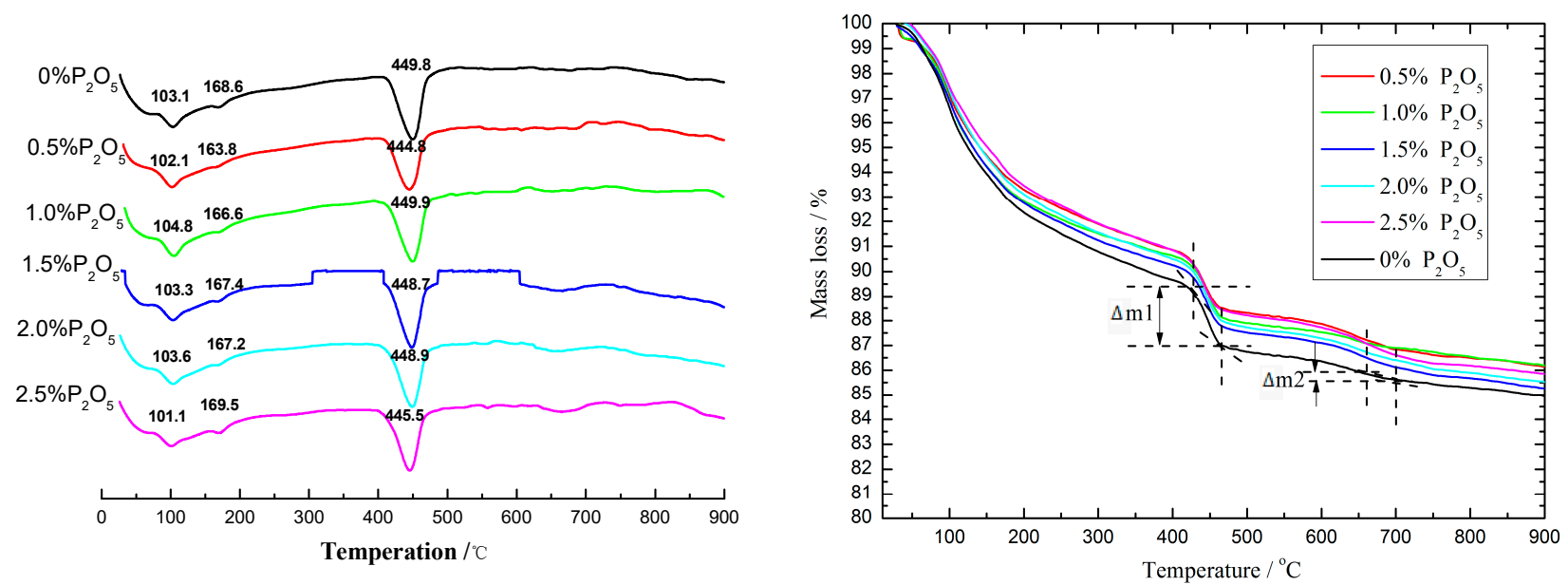

(a)
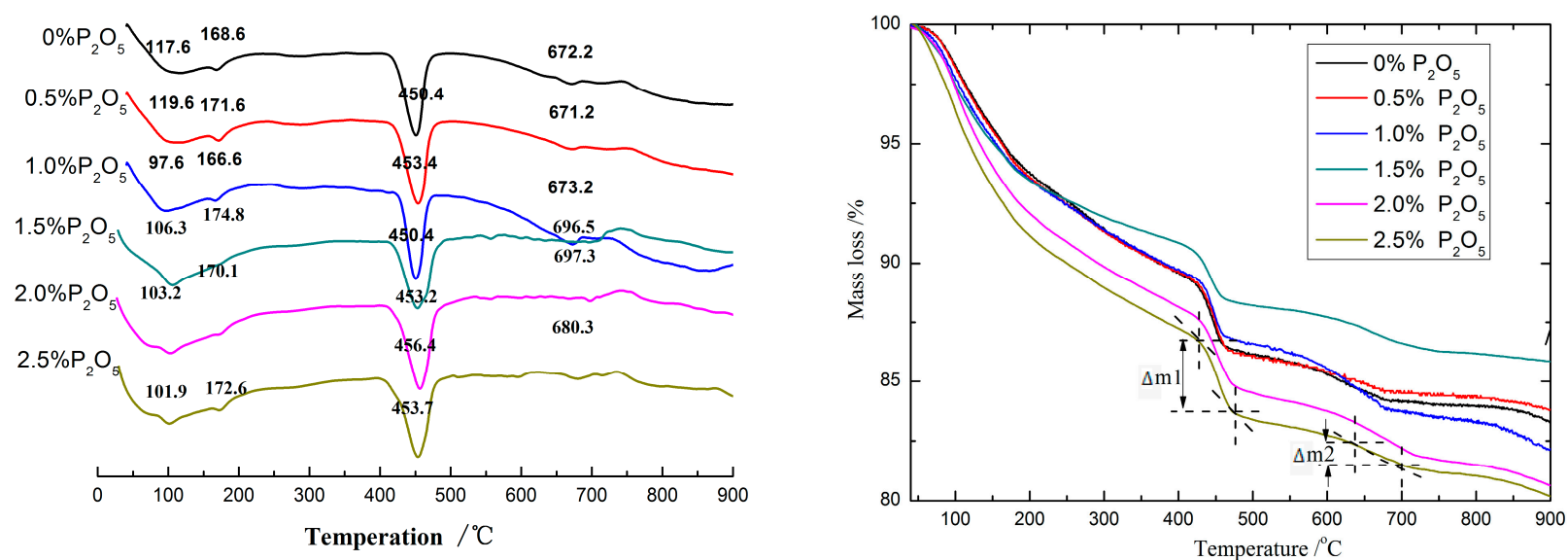

(b)

Figure 7. DSC-TG of cement pastes hydrated for (a) 3 days and (b) 28 days.

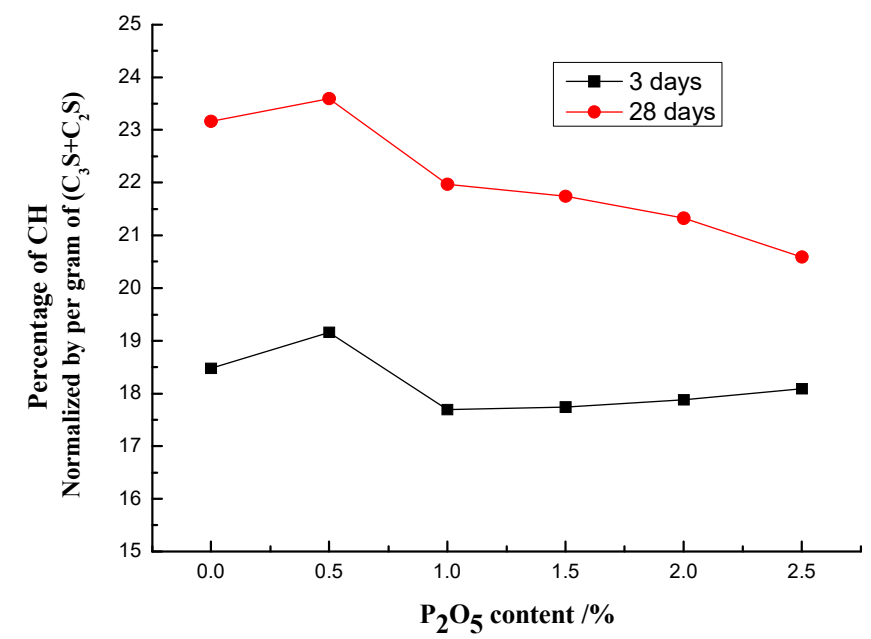

Figure 8. The effect of $\mathrm{P}_{2} \mathrm{O}_{5}$ content in cement clinkers on the formation rate of $\mathrm{Ca}(\mathrm{OH})_{2}$ in cement pastes. 


\subsection{Microstructure of Cement Pastes}

Figure 9 shows the effect of content of $\mathrm{P}_{2} \mathrm{O}_{5}$ on the morphology of hydration products at 3 days by SEM. The main hydration products presented mainly included $\mathrm{CH}$ and $\mathrm{C}$ $\mathrm{S}-\mathrm{H}$. Apparently, with the $0.5 \% \mathrm{P}_{2} \mathrm{O}_{5}$, the microstructure of cement pastes was denser compared to the reference one. It is mainly because more $\mathrm{C}_{3} \mathrm{~S}$ has been formed due to its mineralization and more hydration products can be obtained, which corresponds to the increase in the strength of cement pastes containing $0.5 \% \mathrm{P}_{2} \mathrm{O}_{5}$. For the cement pastes containing both $2.0 \%$ and $2.5 \% \mathrm{P}_{2} \mathrm{O}_{5}$, its microstructure seems looser compared to the reference sample, which is because the phosphorous will reduce the amount of $C_{3} S$ and also lower the hydraulic reactivity of $\mathrm{C}_{2} \mathrm{~S}$, leading to less formation of C-S-H compared to the reference, as the main source of strength. Moreover, it is worth noting that unlike the controlling sample, when the amount of $\mathrm{P}_{2} \mathrm{O}_{5}$ was higher than $2.0 \%$, small particles can be observed on the surface of hydration products, which perhaps introduces new weak interfaces causing a decrease in strength.

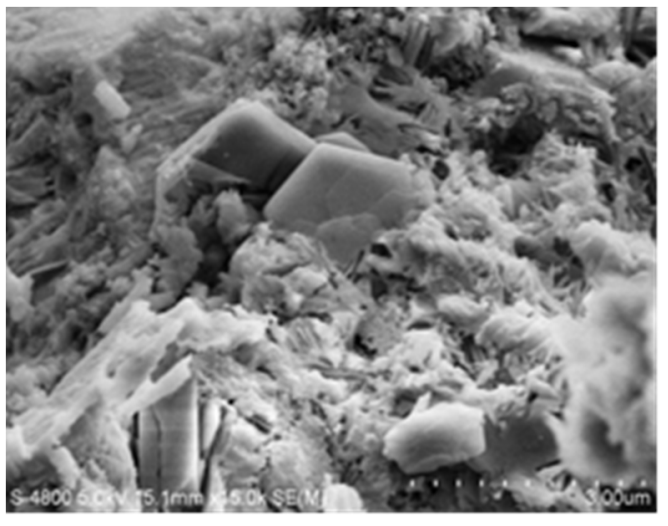

(a)

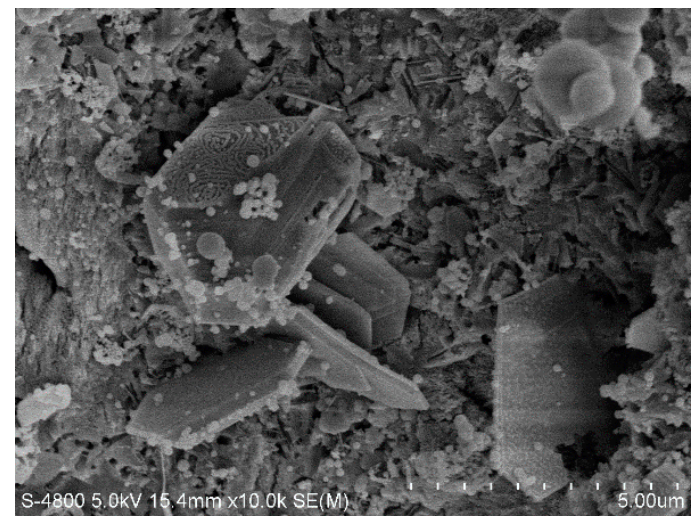

(c)

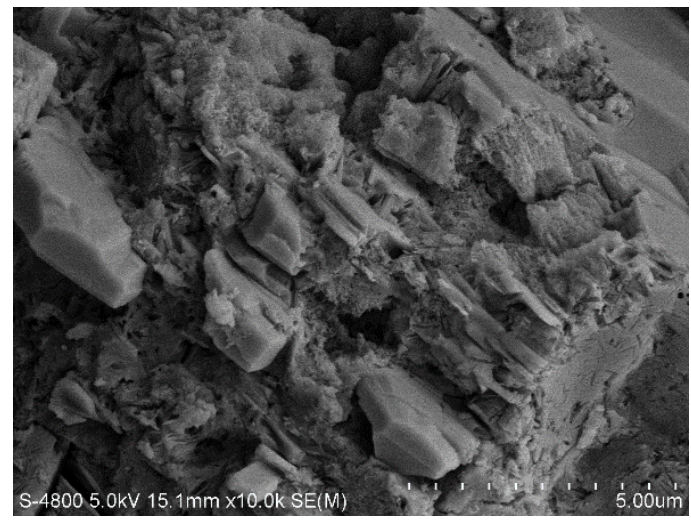

(b)

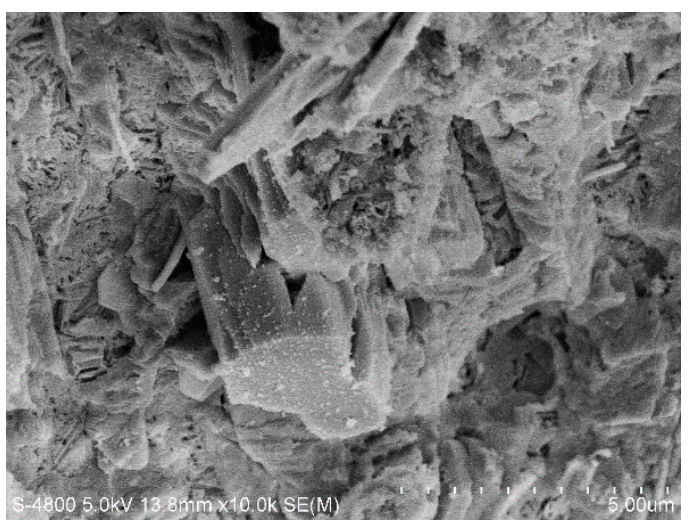

(d)

Figure 9. SEM images of cement pastes hydrated for 3 days. (a) $0 \% \mathrm{P}_{2} \mathrm{O}_{5}$, (b) $0.5 \% \mathrm{P}_{2} \mathrm{O}_{5}$, (c) $2.0 \% \mathrm{P}_{2} \mathrm{O}_{5}$ and (d) $2.5 \% \mathrm{P}_{2} \mathrm{O}_{5}$.

Figure 10 presents the morphology of cement pastes with or without $\mathrm{P}_{2} \mathrm{O}_{5}$ at 28 days. It is apparent that the addition of phosphorous will change the morphology of hydration products, especially for the C-S-H gel. Unlike normal cement pastes, those C-S-H gels generated by the phosphorous-containing cement were more fibrous and the microstructure of cement pastes was looser compared to the plain samples. In fact, based on the various previous work on the morphology changes of C-S-H [27], combining with the results, it can be learned that the addition of phosphorous will make C-S-H present as more fibrous with porous small voids in Figure 10d, which matches well with Li's work. The element composition of C-S-H of cement pastes containing $2 \%$ and $2.5 \% \mathrm{P}_{2} \mathrm{O}_{5}$, after curing for 
28 days was further analyzed by SEM-EDX (Figure 11). Table 4 shows the chemical compositions of C-S-H in cement pastes with $2.0 \%$ and $2.5 \% \mathrm{P}_{2} \mathrm{O}_{5}$ by EDX.

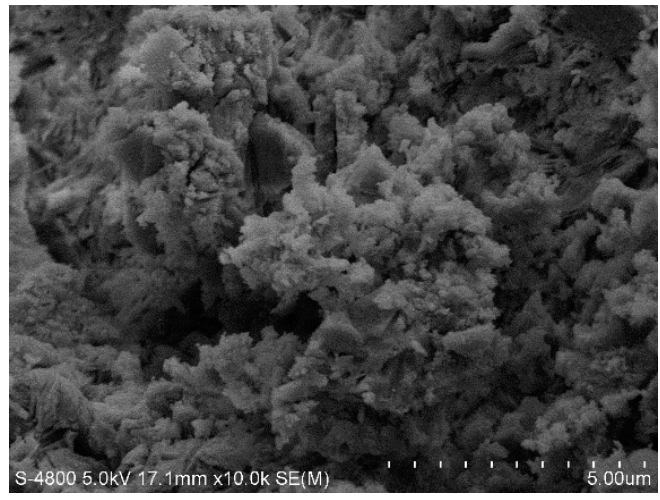

(a)

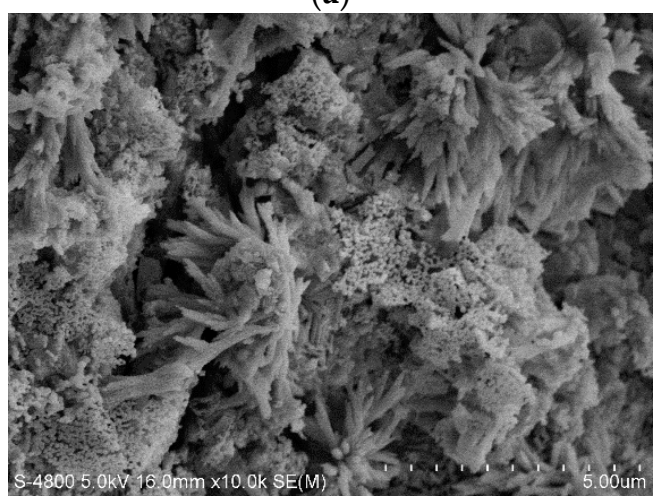

(c)

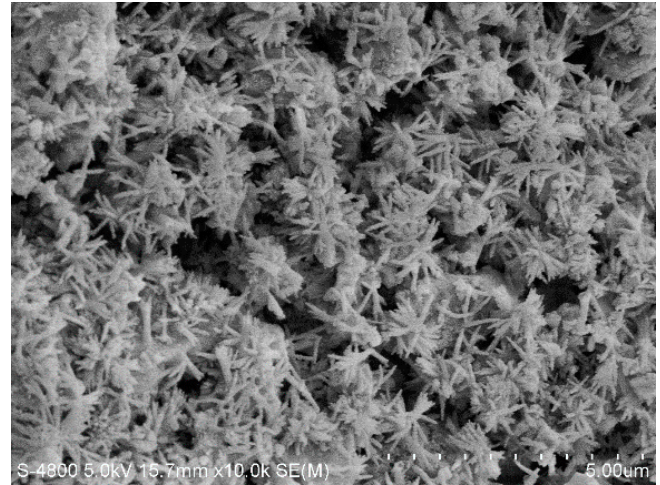

(b)

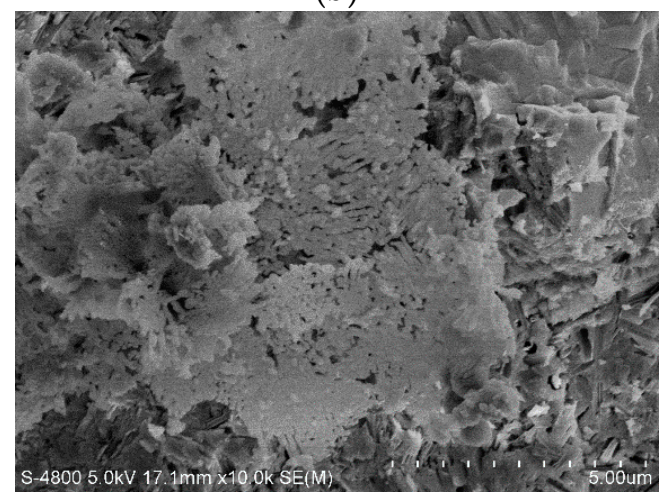

(d)

Figure 10. Morphology of cement pastes at 28 days. (a) $0 \% \mathrm{P}_{2} \mathrm{O}_{5},\left(\right.$ b) $1.5 \% \mathrm{P}_{2} \mathrm{O}_{5}$, (c) $2.0 \% \mathrm{P}_{2} \mathrm{O}_{5}$ and (d) $2.5 \% \mathrm{P}_{2} \mathrm{O}_{5}$.

The results showed that the main elements were calcium, silicate, and oxide, which is similar to normal cement pastes. Phosphorous was also detected in C-S-H gel, and the amount correspondingly increased from $0.09 \%$ to roughly $0.3 \%$. The amount and polymerization degree of C-S-H in paste containing phosphorous are lower in comparison to those in normal Portland cement [28]. In addition, this is probably the main reason to cause the difference in morphology of C-S-H compared to the reference one [29]. Furthermore, similar to those pastes at 3 days, small particles on the surface of hydration products can be observed at 28 days. In addition, for the $2.5 \%$ phosphorous, hydration products will gather. In short, the existence of phosphorous in cement will affect the morphology of hydration products and the microstructure, leading to a decrease in its strength.

Table 4. Chemical composition of C-S-H in cement pastes with $2.0 \%$ and $2.5 \% \mathrm{P}_{2} \mathrm{O}_{5}$ by EDX/wt. $\%$.

\begin{tabular}{ccccccc}
\hline $\mathbf{P}_{\mathbf{2}} \mathbf{O}_{\mathbf{5}}$ in Clinker $/ \%$ & & O-K & Al-K & Si-K & P-K & Ca-K \\
\hline \multirow{2}{*}{2.0} & Point 1 & 66.61 & 3.00 & 5.53 & - & 22.37 \\
& Point 2 & 59.94 & 0.93 & 8.35 & 0.09 & 30.34 \\
\hline \multirow{2}{*}{2.5} & Point 1 & 51.08 & 1.64 & 7.55 & 0.26 & 39.46 \\
& Point 2 & 43.26 & 1.65 & 8.01 & 0.35 & 46.72 \\
\hline
\end{tabular}



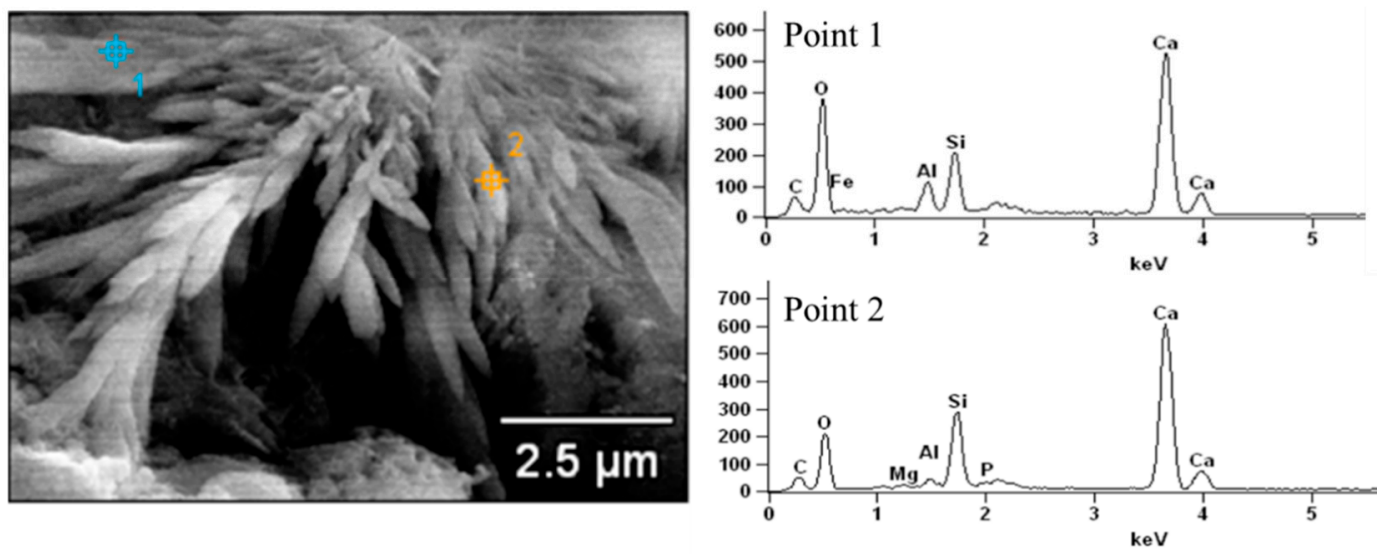

(a)
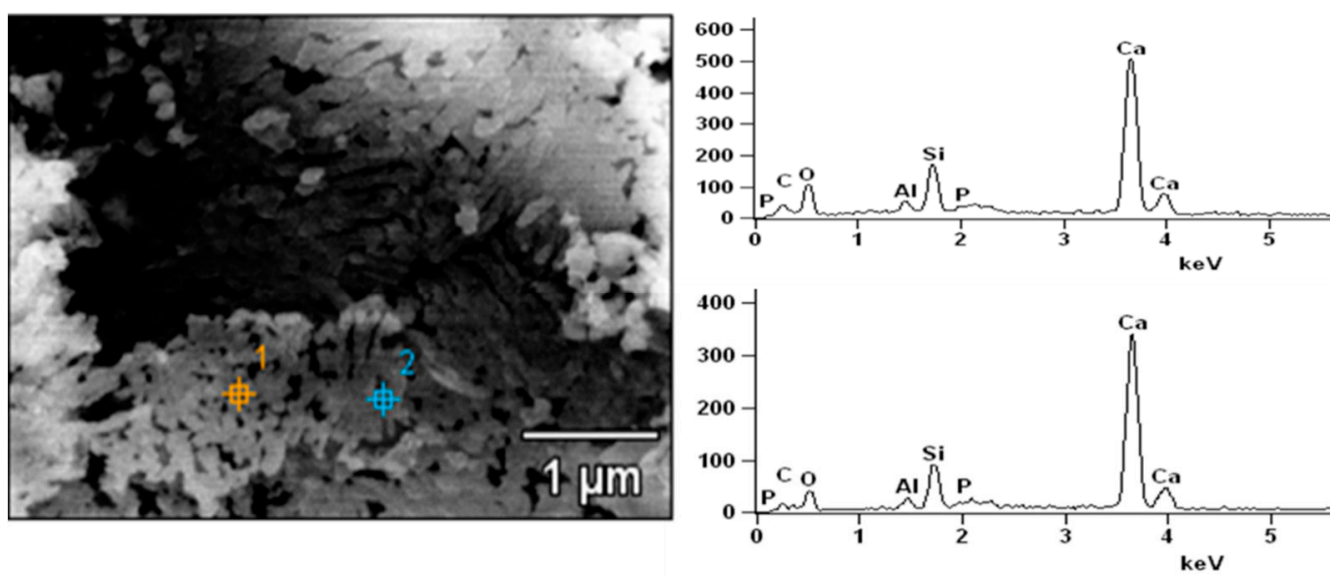

(b)

Figure 11. SEM-EDX analysis of hydration products of C-S-H with phosphorous. (a) $2.0 \% \mathrm{P}_{2} \mathrm{O}_{5}$ and (b) $2.5 \% \mathrm{P}_{2} \mathrm{O}_{5}$.

\subsection{Strength of Cementitious Materials}

\subsubsection{Compressive Strength of Cement Pastes}

The influence of different content of phosphorous on the compressive strength of cement pastes whose $\mathrm{W} / \mathrm{C}$ was 0.28 at 3 days and 28 days is presented in Figure 12 . The results showed that when the content of $\mathrm{P}_{2} \mathrm{O}_{5}$ was $0.5 \%$, the compressive strength of cement pastes at 3 and 28 days was slightly improved by $3.2 \%$ and $1.1 \%$ compared to the controlling sample. However, with the continuous increase of the $\mathrm{P}_{2} \mathrm{O}_{5}$, the compressive strength of the pastes at 3 days and 28 days was correspondingly decreased. When the $\mathrm{P}_{2} \mathrm{O}_{5}$ went up to $2.5 \%$, the compressive strength of cement pastes at 3 days and 28 days decreased by $15.7 \%$ and $16.8 \%$, respectively, compared to the controlling sample. 


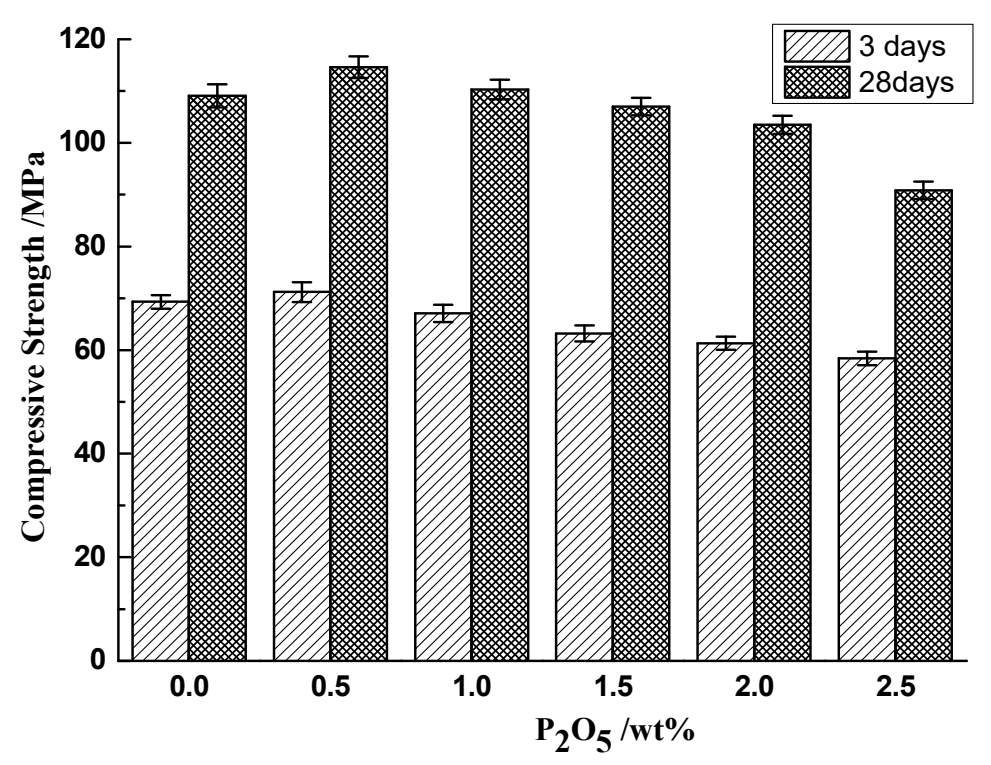

Figure 12. Compressive strengths of the cement pastes prepared with phosphorous-bearing clinkers and hydrated for 3 and 28 days.

\subsubsection{Strength of Mortars}

In addition to the strength of cement pastes, the strength of the mortars containing different contents of phosphorous prepared according to the method of testing cementsDetermination of strength GB/T17671-1999 was measured after curing for $3 \mathrm{~d}$ and $28 \mathrm{~d}$, as shown in Figure 13.

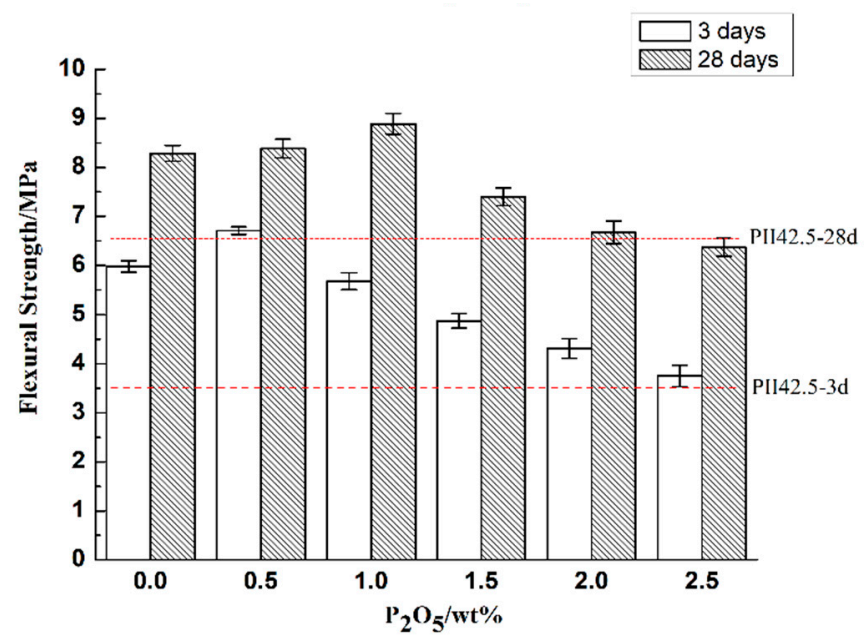

(a)

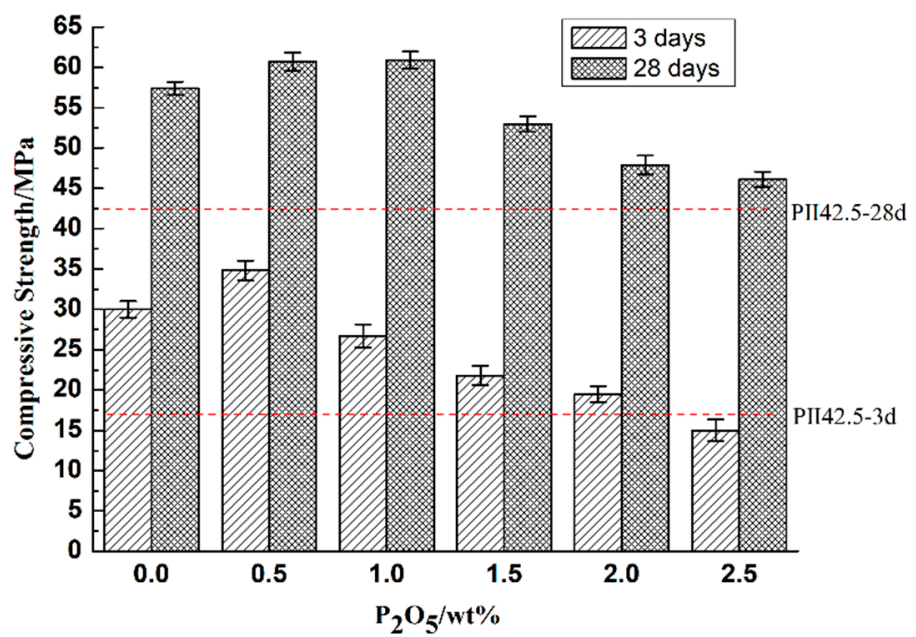

(b)

Figure 13. (a) Flexural and (b) Compressive strength of mortars cured in water for 3 and 28 days.

Regarding with those samples cured for 3 days, the development of both compressive and flexural strength of mortar were basically consistent with the compressive strength of cement pastes; specifically, it will be slightly promoted with $0.5 \%$ phosphorous and then gradually decreased with the increase of phosphorous. However, for those samples cured for 28 days, except for $0.5 \% \mathrm{P}_{2} \mathrm{O}_{5}$, the flexural and compressive strength of mortar containing $1.0 \% \mathrm{P}_{2} \mathrm{O}_{5}$ increased by $7.2 \%$ and $6.1 \%$ respectively. Then, the strength of mortars exerted a significant decrease with the increase of phosphorous. When the content of $\mathrm{P}_{2} \mathrm{O}_{5}$ was $2.5 \%$, the flexural and compressive strength were separately reduced by $23.2 \%$ and $19.7 \%$. However, it is worth noticing that according to the requirement of Chinese 
standards for the cement industry, even the $\mathrm{P}_{2} \mathrm{O}_{5}$ was high at $2.0 \%$; it can still meet its requirement of P.II 42.5, which means that it is feasible to use phosphorous limestone as raw materials to produce Portland cement.

\subsection{Discussion}

It is well known that cement hydration is a dissolution-participation process, which is closely related to the properties of cement clinker, particularly for mineral composition and its crystal structures. The existence of phosphorous in cement surely exerts significant influence on the hydration process, representing changes in strength. At the early stage of 3 days, the strength of cement pastes and mortars containing $0.5 \% \mathrm{P}_{2} \mathrm{O}_{5}$ can be enhanced due to its mineralization effect, causing more $\mathrm{C}_{3} \mathrm{~S}$ formation, meaning more C-S-H gel can be obtained. However, at later stage of 28 days, the strength of mortars containing 1.0\% $\mathrm{P}_{2} \mathrm{O}_{5}$ were also improved. It can be speculated that despite a decrease in $\mathrm{C}_{3} \mathrm{~S}$, more $\mathrm{C}_{2} \mathrm{~S}$ can be formed, which is more positive for promotion at a later stage. However, with an increase of $\mathrm{P}_{2} \mathrm{O}_{5}$, on the one hand, the amount of $\mathrm{C}_{3} \mathrm{~S}$ will decrease and more $\beta-\mathrm{C}_{2} \mathrm{~S}$ will transfer into $\alpha^{\prime}-C_{2} S$. Furthermore, phosphorous will dissolve into minerals and participate in the hydration. As a result, with the hydration of silicate phase, more phosphorous in solid solution will come out, which may react with $\mathrm{Ca}^{2+}$ to form $\mathrm{Ca}_{3}\left(\mathrm{PO}_{4}\right)_{2}$ precipitated on the surface of hydration products and anhydrate clinker particles, inhibiting its hydration and prolonging the induction period as showed in the hydration heat flow. However, according to the XRD results, no $\mathrm{Ca}_{3}\left(\mathrm{PO}_{4}\right)_{2}$ has been detected, which we speculate is for two reasons: (1) not enough $\mathrm{Ca}_{3}\left(\mathrm{PO}_{4}\right)_{2}$ has been used to be detected; (2) as mentioned, the existence of phosphorous will change the structure of silicate phases, especially for $C_{2} S$ from $\beta-C_{2} S$ gradually to $\alpha^{\prime}-\mathrm{C}_{2} \mathrm{~S}$, leading to the different morphology of C-S-H gel, as shown in Figure 10. In fact, the hydration heat flow ratio at the accelerated period to some extent indicates that the growth ratio of C-S-H slightly decreased, which was constant with $\mathrm{Wu}^{\prime}$ 's reports that phosphorous can affect the crystal structure of $C_{2} S$ and reduce its reactivity [30]. Furthermore, unlike normal cement hydration processes, the aforementioned results explain that the use of phosphorous-bearing limestone exert a greater impact on the property of $\mathrm{C}_{2} \mathrm{~S}$ than on $\mathrm{C}_{3} \mathrm{~S}$. The formation of a new phase of $\alpha^{\prime}-\mathrm{C}_{2} \mathrm{~S}-\mathrm{xC}_{3} \mathrm{P}$ whose hydration activity will dramatically decrease is demonstrated based on the results of XRD. This is opposite to previous results regarding the influence of the addition of phosphorous-related chemical analytic agents on the $\mathrm{C}_{2} \mathrm{~S}$ structure and its hydraulic hydration. However, accounting for instances [27] where different ions and concentrations will change the morphology of C-S-H, specifically the addition of phosphorous in the solutions will make the C-S-H have more fibrils and also be more porous with small voids, which agreed well with other researchers' work [20,31]. Therefore, it is apparent that the influence of phosphorous introduced separately by industrial raw materials and chemical analytical agents will exert different effects on both the structure and activity of $\mathrm{C}_{2} \mathrm{~S}$, but has similar morphology of $\mathrm{C}-\mathrm{S}-\mathrm{H}$. In short, the large amount of phosphorous in those mineral phases, particularly for $\mathrm{C}_{2} \mathrm{~S}$ by $\alpha^{\prime}-\mathrm{C}_{2} \mathrm{~S}-\mathrm{xC}_{3} \mathrm{P}$, will undoubtedly dissolve into solutions, prolong the induction period, decrease the hydration heat flow, and change the microstructure of cement pastes, leading to the decrease in its strength. Again, unlike the phosphorous-bearing cement clinker introduced by chemical agents, it will be more effective to study the hydration and strength development of cementitious materials prepared with phosphorous-bearing clinkers.

\section{Conclusions}

A systematic investigation about the mechanical properties of phosphorous-containing cement and its hydration mechanism was carried out. Specifically,

(1) When the $\mathrm{P}_{2} \mathrm{O}_{5}$ in the clinker is $0.5 \%$, both compressive and flexural strength of cement pastes will be improved separately at 3 and 28 days, while with the continuous increase of $\mathrm{P}_{2} \mathrm{O}_{5}$, the strength of cement pastes will decrease; for mortars, when the content of $\mathrm{P}_{2} \mathrm{O}_{5}$ is $1.0 \%$, the compressive and flexural strength of mortars for 28 days can still be promoted. However, for others, the addition of phosphorous will be 
harmful for the strength of mortars. Moreover, even the $\mathrm{P}_{2} \mathrm{O}_{5}$ in the clinker is as high as $2.0 \%$, and the cement can still meet the requirements of P.II 42.5 (Chinese standard).

(2) The existence of phosphorous in the clinker will seriously prolong the induction period and decrease the total hydration heat. Despite those small particles on the surface hydration products, no new hydration products for phosphorous-containing cement have been detected. However, C-S-H gel for the pastes containing phosphorous will present as fiber-like, and it is also thicker than the plain one. Moreover, the microstructure for cement pastes containing phosphorous will be looser compared to normal cement pastes.

(3) However, unlike $\mathrm{C}_{2} \mathrm{~S}$, it can be speculated that the hydration reactivity of the new phase of $\alpha^{\prime}-\mathrm{C}_{2} \mathrm{~S}-\mathrm{x} \mathrm{C}_{3} \mathrm{P}$ is rather lower based on the XRD results, leading to the less formation of hydration products and poor structure of cement pastes or mortars, directly causing poor mechanical property.

(4) A special type of P.O 42.5 cement has been produced, which can prove the workability of the use of low-grade phosphorous limestone as the raw materials for cement production, not only providing a significant guidance for actual industrial cement production but also greatly cutting the production cost. However, its application may only be aimed at projects that require a long setting time.

Author Contributions: Data curation, L.X., J.T. and K.L.; Formal analysis, K.L., and M.D.; Supervision, M.D.; Writing—original draft, L.X.; Writing—review \& editing, J.T., and M.D. All authors have read and agreed to the published version of the manuscript.

Funding: This research was financially supported by Natural Science Foundation of the Anhui Higher Education Institutions (KJ2020A0476).

Institutional Review Board Statement: Not applicable.

Informed Consent Statement: Not applicable.

Data Availability Statement: The data presented in this study are available on request from the corresponding author.

Conflicts of Interest: The authors declare no conflict of interest.

\section{References}

1. Lieber, W. The influence of phosphates on the hydration of Portland cement. In Proceedings of the sixth International Congress on the Chemistry of Cement, Moscow, Russia, 23-27 September 1974.

2. Lieber, W. Effect of inorganic admixtures on the setting and hardening of Portland cement. Zement-Kalk-Gips 1973, 26, 75-79.

3. Chen, X.; Fang, K.H.; Yang, H.Q.; Peng, H. Hydration kinetics of cement-based materials with $\mathrm{P}_{2} \mathrm{O}_{5}$ incorporated. J. Civ. Architect. Environ. Eng. 2010, 32, 119-124.

4. Nurse, R.W. The effect of phosphate on the constitution and hardening of Portland cement. J. Appl. Chem. 1952, 2, 708-713. [CrossRef]

5. Benard, P.; Garrault, S.; Nonat, A.; Cau-Dit-Coumes, C. Hydration process and rheological properties of cement pastes modified by orthophosphate addition. J. Eur. Ceram. Soc. 2005, 25, 1877-1883. [CrossRef]

6. Boughanmi, S.; Labidi, I.; Megriche, A.; Tiss, H.; Nonat, A. Does phosphorus affect the industrial Portland cement reactivity. Constr. Build. Mater. 2018, 188, 599-606. [CrossRef]

7. Gutt, W. Manufacture of Portland Cement from Phosphatic Raw Materials. In Proceedings of the 5th International Symposium on the Chemistry of Cement, Tokyo, Japan, 7-11 October 1968.

8. Ifka, T.; Palou, M.T.; Bazelova, Z. Influence of $\mathrm{CaO}$ and $\mathrm{P}_{2} \mathrm{O}_{5}$ of bone ash upon the reactivity and the burnability of cement raw mixtures. Ceramics-Silikáty 2012, 56, 76-84.

9. Tong, X.L.; Zhang, X.D. Effect of phosphate on the mineral composition of Portland cement clinker. J. Chin. Ceram. Soc. 1986, 14, 56-62.

10. Boughanmi, S.; Labidi, I.; Megriche, A.; Maaoui, M.E.; Nonat, A. Natural fluorapatite as a raw material for Portland clinker. Cem. Concr. Res. 2018, 105, 72-80. [CrossRef]

11. Guan, Z.F.; Chen, Y.M.; Guo, S.H.; Qin, S.W. Effect of phosphorus slag, phosphorus Mineral or phosphorus tailings on highstrength Portland Clinker. B. Chin. Ceram. Soc. 2005, 3, 81-82.

12. Zhou, S.T.; Li, X.B.; Zhou, Y.N.; Min, C.D.; Shi, Y. Effect of phosphorus on the properties of phosphogypsum-based cemented backfill. J. Hazard. Mater. 2020, 399, 122993. [CrossRef] 
13. Zhang, Z.Q.; Wang, Q.; Yang, J. Hydration mechanisms of composite binders containing phosphorus slag at different temperatures. Constr. Build. Mater. 2017, 147, 720-732. [CrossRef]

14. Mehdi, M.; Mickael, S.; Thierry, C.; Loic, D.; Arezki, T.H. Hydration mechanisms of sewage sludge ashes used as cement replacement. Cem. Concr. Res. 2020, 135, 106115.

15. Fernando, C.H.; Holger, S.; Valdecir, A.Q. Influence of phosphorus from phosphogypsum on the initial hydration of Portland cement in the presence of superplasticizers. Cem. Concr. Compos. 2017, 83, 384-393.

16. Zheng, K.R.; Zhou, J.; Mulbah, G. Influences of phosphate tailings on hydration and properties of Portland cement. Constr. Build. Mater. 2015, 98, 593-601. [CrossRef]

17. Cheng, L.; Sheng, G.H.; Pi, Y.L.; Zhu, C.G. Effect of Retardation Mechanism of Phosphorous Slag on Portland Cement. Bull. Chin. Ceram. Soc. 2005, 4, 40-42.

18. Duda, W.H. International Cement Process Information Collection; China Construction Industry Press: Beijing, China, 1981.

19. Gartner, E.M.; Young, J.F.; Damidot, D.A. Hydration of Portland cement. In Structure and Performance of Cement, 2nd ed.; Bensted, J., Barnes, P., Eds.; Spon Press: New York, NY, USA, 2002.

20. Li, J.Q.; Geng, G.Q.; Zhang, W.X.; Yu, Y.S.; Shapiro, D.A.; Monteiro, P.J.M. The Hydration of $\beta$ - and $\alpha^{\prime}{ }_{\mathrm{H}}$-Dicalcium Silicates: An X-ray Spectromicroscopic Study. ACS Sustain. Chem. Eng. 2019, 7, 2316-2326. [CrossRef]

21. Chen, W.Y.; Tu, H. Application of TG-DSC technique in the study of cement. Anal. Instrum. 2012, 2, 55-58.

22. Sha, W.; Neill, E.A.O.; Guo, Z. Differential scanning calorimetry study of ordinary Portland cement. Cem. Concr. Res. 1999, 29, 1487-1489. [CrossRef]

23. Sha, W.; Pereira, G.B. Differential scanning calorimetry study of hydrated ground granulated blast-furnace slag. Cem. Concr. Res. 2001, 31, 327-329. [CrossRef]

24. Noirfontaine, M.N.; Nenez, S.T.; Frehel, M.S.; Gasecki, G.; Labianca, C.G. Effect of phosphorus impurity on tricalcium silicate T1: From synthesis to structural characterization. J. Am. Ceram. Soc. 2009, 92, 2337-2344. [CrossRef]

25. Kwon, W.T.; Kim, Y.H.; Chu, Y.S. Effect of $\mathrm{P}_{2} \mathrm{O}_{5}$ and Chloride on clinker reaction. J. Mater. Online 2005, 1, 1-8.

26. Diouri, A.; Boukhari, A.; Aride, J.; Puertas, F.; Vazquez, T. Stable $\mathrm{Ca}_{3} \mathrm{SiO}_{5}$ solid solution containing manganese and phosphorus. Cem. Concr. Res. 1997, 27, 1203-1212. [CrossRef]

27. Richardson, I.G. Tobermorite/jennite-and tobermorite/calcium hydroxide-based models for the structure of CSH: Applicability to hardened pastes of tricalcium silicate, $\beta$-dicalcium silicate, Portland cement, and blends of Portland cement with blast-furnace slag, metakaolin, or silica fume. Cem. Concr. Res. 2004, 34, 1733-1777.

28. Wang, L.; Guo, F.X.; Lin, Y.Q.; Yang, H.M.; Tang, S.W. Comparison between the effects of phosphorous slag and fly ash on the C-S$\mathrm{H}$ structure, long-term hydration heat and volume deformation of cement-based materials. Constr. Build. Mater. 2020, $250,118807$. [CrossRef]

29. Guo, C.Z.; Zhu, J.Q.; Zhou, W.B.; Sun, Z.; Chen, W. Effect of phosphorous and fluorine on hydration process of tricalcium silicate and tricalcium aluminate. J. Wuhan Univ. Technol. 2012, 27, 333-336. [CrossRef]

30. Wu, W.X. The Effect of Fluorapatite in the Limestone on the Composition and Property of Clinker; Nanjing Tech University: Nanjing, China, 2015.

31. Li, J.Q.; Zhang, W.X.; Xu, K.; Monteiro, P.J.M. Fibrillar calcium silicate hydrate seeds from hydrated tricalcium silicate lower cement demand. Cem. Concr. Res. 2020, 137, 106195. [CrossRef] 